\title{
Application of Integrated Reservoir Management and Reservoir Characterization to Optimize Infill Drilling
}

\author{
Quarterly Report \\ December 13, 1997 - March 12, 1998
}

Work Performed Under Contract No.: DE-FC22-94BC14989

\author{
For \\ U.S. Department of Energy \\ Office of Fossil Energy \\ Federal Energy Technology Center \\ P.O. Box 880 \\ Morgantown, West Virginia 26507-0880
}

By

Fina Oil \& Chemical Company

6 Desta Drive

Suite 4400

Midland, Texas 79701 


\section{Disclaimer}

This report was prepared as an account of work sponsored by an agency of the United States Government. Neither the United States Government nor any agency thereof, nor any of their employees, makes any warranty, express or implied, or assumes any legal liability or responsibility for the accuracy, completeness, or usefulness of any information, apparatus, product, or process disclosed, or represents that its use would not infringe privately owned rights. Reference herein to any specific commercial product, process, or service by trade

name, trademark, manufacturer, or otherwise does not necessarily constitute or imply its endorsement, recommendation, or favoring by the United States Government or any agency thereof. The views and opinions of authors expressed herein do not necessarily state or reflect those of the United States Government or any agency thereof. 
FINA OIL \& CHEMICAL COMPANY

QUARTERLY TECHNICAL PROGRESS REPORT

\begin{abstract}
"APPLICATION OF INTEGRATED RESERVOIR MANAGEMENT AND RESERVOIR CHARACTERIZATION TO OPTIMIZE INFILL DRILLING"
\end{abstract}

INSTRUMENT NO. DE-FC22-94BC14989--16

NORTH ROBERTSON UNIT DEPARTMENT OF ENERGY CLASS II OIL PROGRAM PROJECT

REPORTING PERIOD: 12/13/97 TO 03/12/98

This Quarterly Progress Report summarizes the technical progress of the project from 12/13/97 TO 03/12/98.

\title{
ACTIVITY II.1 - MANAGEMENT AND ADMINISTRATION
}

PROJECT MANAGEMENT AND ADMINISTRATION - TASK II.1.1

\section{Project Status}

The eighteen 10-acre infill wells which were drilled as part of the field demonstration portion of the project are all currently in service with no operational problems. These wells consist of fourteen producing wells and four injection wells. The producing wells are currently producing a total of approximately 400 bopd, down from a peak rate of 900 bopd. Unit production is currently averaging approximately 2,600 bopd, 12,000 bwpd and 18,000 bwipd.

\section{ACTIVITY II.2 - FIELD DEMONSTRATION}

\section{FIELD OPERATION \& SURVEILLANCE - TASK II.2.2}

\section{Inter-Well Tracer Program}

An inter-well tracer program was designed for the North Robertson Unit with the objective of obtaining critical information in regards to preferential ( directional ) fluid flow, breakthrough time between injectors and producers, and to evaluate the potential of direct communication between injector and producer. The wells selected for the tracer program are Wells \#3539 \& \#1504. The goal in the selection of a tracer material for the injected water was to choose a tracer that would travel through the formation with the injected water and whose behavior would mimic that of the water. 
There exist a number of good water phase tracers currently available, each having their own distinct advantages and disadvantages. The tracers can be divided into two main groups, chemical tracers and radioactive tracers.

The chemical tracers would include thiocyanate ion, iodide ion, bromide ion, nitrate ion, low molecular weight alcohols and various types of fluorescent dyes. Their advantages are that they are relatively inexpensive and usually can be detected at low concentrations by gas chromatography or analytical chemical methods. Their principal disadvantage is the logistics that may be involved in their use. Under certain design situations, such as large distances between wells or thick pay sections, tens of thousands of pounds of chemical may be required to obtain the minimum analyzable concentration at the producing wells. The cost associated with the transportation of that amount of chemical to location, the time involved in mixing the chemical in a base fluid and injection of the chemical into the well may over shadow the cost of the chemical itself. Under these conditions, the total cost of using chemicals as a tracer may be significantly higher than the use of radioactive materials.

Currently available radioactive tracers for waterflood applications include tritium, the radioactive isotope of hydrogen, in the form of tritiated water, thiocyanate ion labeled with carbon fourteen, and the isotope cobalt 60 in the form of cobalt hexacyanide. The radioactive tracers have the advantage that they can be identified in extremely low concentrations (parts per billion) therefore, only very small amounts need to be injected. This also allows for easier transport and injection as compared with chemical tracers. Their only disadvantages are that, due to the fact that the materials are radioactive, only trained/certified personnel can handle them and some of the analysis techniques are more costly than in the case of chemical tracers.

Of the water phase radioactive tracers, tritiated water is the preferred material and is the standard by which all other tracers are judged. Since it is water, it has the exact flow properties of the injected water and, therefore, will behave analogous to the injected water in the formation. This means that there will be no lagging the flood front or holdup in the reservoir. In addition, tritiated water is a beta emitter, meaning that it gives off low energy radiation, thereby requiring only very thin shielding. In fact, in the concentrations found in the produced water during a tracer test, the radiation is so low that it will not penetrate a sheet of paper. Of the water phase radioactive tracers, tritiated water is the lowest cost, easiest to detect, and has an excellent record of successful use as a water phase tracer.

The next most frequently used water phase tracer is thiocyanate ion. It behaves as a non-adsorbing anion (such as chlorine ion) in the reservoir and will travel through the reservoir without loss. It can be used in a normal chemical form, as discussed above, or a radioactive carbon fourteen atom can be substituted for the carbon twelve atom. In this form it is known as labeled thiocyanate. This substitution makes it possible to analyze for the tracer at very low concentrations as is done in the radiocarbon dating on archaeological specimens. The main advantage of carbon fourteen labeled materials is that only small amounts are required for tracer applications. For example, $10 \mathrm{Ci}$ of labeled thiocyanate would produce approximately the same detectable concentrations as several thousand pounds of thiocyanate in the normal chemical form. The main disadvantage of the labeled thiocyanate is that the analysis is more complicated, and thereby more costly than the analysis for chemical thiocyanate. 
The third most widely used radioactive water phase tracer is cobalt hexacyanide. It is a gamma emitter and therefore has a slightly higher energy level than tritiated water. It is extremely stable at higher temperatures and due to its anionic nature will not be adsorbed onto the clays on the formation face. It has all the advantages of the other, previously discussed, water phase radioactive tracers. Its main disadvantage is that due to the analysis technique used, larger samples are required than with the other radioactive tracers.

In selecting the best materials to be used as tracers for a project, the following areas are always considered:

1. Environmental safety

2. Detectability

3. Stability in the reservoir

4. Economics

During the design process for the tracer program, sensitivities are performed to assure that the peak concentrations predicted at the producer wells never exceed the NPC unrestricted discharge limit for the subject tracer. In other words, the levels allowed by the NPC in drinking water. This guideline is used for both chemical and radioactive tracers. The end result is that tracer quantities were chosen so that the produced fluids will be nonhazardous and detection levels will be within an effective analytical range even when assuming wide variations in flow patterns.

For the investigation of possible communication in each pattern it is recommended that one chemical and one radioactive interwell tracers be used. Both of the recommended tracers, tritiated water and fluorescent dye, are good water phase racers, as discussed above, and when used in combination can give additional reservoir information not available when using only a single tracer. The combined use of these tracers allows the distinguishing between communication down a fracture and communication through a high permeability layer. This can be extremely important as the exact cause of the communication will dictate the type of workover required to shut-off the communication.

The exact quantity of each tracer to be used is based on the distance between injectors and producers, the volume of injected water treated, the permeability distribution existing in the reservoir, the analytical limits of the tracer and mixing which occurs in the reservoir. A streamtube type simulator, based on the work of Brigham, was used to model the flow of tracer in each formation layer. This streamtube simulator was used to calculate the amount of each tracer material required at the injector in each pattern area to result in a detectable concentration at the producing wells surrounding the subject injector.

The reservoir properties in each of the pattern areas were assumed to be the same except for the net and gross thickness of the Clearfork formation. These properties are summarized in the following table: 


\begin{tabular}{|l|ll|}
\hline \multicolumn{1}{|c}{ Reservoir Property } & \multicolumn{1}{c}{$\begin{array}{c}\text { Pattern Area \#1 } \\
\text { (WIW\#1504) }\end{array}$} & $\begin{array}{c}\text { Pattern Area \#2 } \\
\text { (WIW\#3539) }\end{array}$ \\
\hline Gross Thickness & 565 feet & 300 feet \\
\hline Net Thickness & 430 feet & 250 feet \\
\hline Avg. Porosity & $7.5 \%$ & $7.5 \%$ \\
\hline Avg. Permeability & $1.5 \mathrm{md}$ & $1.5 \mathrm{md}$ \\
\hline Permeability Range & $0.001-100 \mathrm{md}$ & $0.001-100 \mathrm{md}$ \\
\hline Avg. Water Saturation & $60 \%$ & $60 \%$ \\
\hline
\end{tabular}

The initial set of simulation runs were based on "average" Clearfork reservoir properties for each well and actual injection and producing rates in each pattern. The first case in each pattern area was run using the total net pay thickness. A sensitivity was also run using only the percentage of net pay taking fluid in each injection well. This thickness was determined from analysis of the injectivity profiles run on each subject injector. Table No. 1 summarizes the results of these base case and model sensitivities cases.

\begin{tabular}{|l|c|c|c|c|}
\hline \multicolumn{2}{|c|}{ MODEL PROPERTIES } & \multicolumn{2}{c|}{ PATTERN AREA \#1 } & \multicolumn{2}{c|}{ PATTERN AREA \#2 } \\
\hline Kavg (md) & & 1.5 & 1.5 & 1.5 \\
\hline Porosity (\%) & 1.5 & 7.5 & 7.5 & 7.5 \\
\hline Sw (\%) & 7.5 & 60 & 60 & 60 \\
\hline Total h (ft) & 430 & 235 & 250 & 50 \\
\hline $\begin{array}{l}\text { Dykstra-Parson's } \\
\text { Permeability Coefficient (v) }\end{array}$ & 0.82 & 0.82 & 0.82 & 0.82 \\
\hline Injection rate (bwipd) & 67 & 67 & 10 & 10 \\
\hline Producing rate (bfpd) & 60 & 60 & 229 & 229 \\
\hline Tritiated Water (Ci) & $\mathbf{1 . 9}$ & $\mathbf{1 . 0}$ & $\mathbf{2 0}$ & $\mathbf{3 . 0}$ \\
\hline Breakthrough Time (days) & $\mathbf{7 1 6}$ & $\mathbf{3 9 1}$ & $\mathbf{2 4 1 1}$ & $\mathbf{4 8 2}$ \\
\hline
\end{tabular}

Table No. 1: Summary of Model Simulation Runs Showing Thickness Sensitivities

Based on these model runs (and others) it was recommended that 1 curie of tritiated water be injected into well \#1504 and 3 curies injected into well \#3539. This should allow for reasonable breakthrough times and result in detectable tracer concentrations at the offset producing wells. The tritiated water was injected into both wells on March 24, and the sampling process was begun. 


\section{Sampling Program}

Samples of the produced water were analyzed prior to injection of any tracer to obtain a background reading of existing chemicals in the reservoir. Following the injection of the tracer, samples of the produced water are being taken at predetermined intervals and analyzed for the presence of tracer.

The following sampling schedule was recommended for the interwell tracer program proposed above:

\begin{tabular}{c}
$\begin{array}{c}\text { Time } \\
\text { (weeks) }\end{array}$ \\
\hline Base \\
1 \\
$2-4$ \\
$5-20$ \\
$21-78$
\end{tabular}

\begin{tabular}{c}
$\begin{array}{c}\text { Sample } \\
\text { Frequency } \\
\text { (per well) }\end{array}$ \\
\hline 1 sample \\
1 per day \\
3 per week \\
1 per week \\
2 per month
\end{tabular}

\begin{tabular}{c}
$\begin{array}{c}\text { Number of } \\
\text { Samples } \\
\text { (per well) }\end{array}$ \\
\hline 1 \\
7 \\
9 \\
16 \\
29
\end{tabular}

Total samples per well for 1.5 years: 62

The tracer will remain in the reservoir for an indefinite period of time. The presence of watered out intervals, fractures, poor cement bond, or faults in the field can lead to rapid breakthrough. For this reason it is extremely important that samples be taken frequently immediately after (if not during) tracer injection. Less frequent samples are necessary as time goes on.

Every third sample will be analyzed for detection of the tracer. If tracer is detected, then back samples will also be analyzed to determine the exact time of breakthrough. Following this schedule, there would be a total of 62 samples/ 21 analyses per well for the first 1.5 years.

\section{Magnetohydrodynamics}

One of the major operational problems at the North Robertson Unit is the existence of paraffins and scales in both the produced and injected fluids. In an effort to reduce the amounts of both paraffin and scale in these fluids, magnetic fluid conditioning tools were placed in strategic locations to test their effectiveness in several different situations. In early March, tools were placed in the production string on 3 producing wells, Nos. 1203, 2228 \& 604, on Injection well \#3101, and on the 6" water transfer line running from Battery \#3 to the central injection facility. Millipore filter tests were run prior to installation at these locations in order to monitor effectiveness. The first set of test data are provided at the conclusion of this section.

Paraffins in crude oil formations normally are in a liquid state, but precipitate from the crude when the equilibrium temperature and pressure change. As crude oil comes up the production tubing, the majority of cooling occurs in the flowing fluid as gas breaks out of solution. This cooling effect 
causes paraffin crystals to form in the flowing liquid. This is defined as the cloud point. Because of their often tacky nature, the adhere to and build up on tubing walls. Where flow lines are exposed to significantly colder outside temperatures, the pipe wall itself can also become a site for deposition.

Paraffin formation and deposition take place by four mechanisms: chemical, mechanical, electrical and thermal. A properly designed magnetic system can alter the chemical, mechanical, and electric properties of the crude as it passes through the magnetic fields. These changes have the effect of also altering the thermal (cloud point) mechanism.

Magnetic Fluid Conditioning tools work by directing fluids through strong permanent magnetic fields within the tool. This alters the physical characteristics of crude by increasing the solubility of the oil and decreasing the cloud point (up to 60 degrees F.), pour point and viscosity. The altered growth pattern of paraffin and scale crystals decreases the sediment and emulsions formed by the paraffin and water molecules locking together which in turn inhibits the buildup of solids in the well and production equipment.

Crude oil is a hydrocarbon/mineral mixture with varying chain lengths and electrical potential. In its natural state there is randomness to the orientation of the molecules. A magnetic field will interact with any substance that carries a charge in any fluid. As charged crystal nuclei pass through magnetic fields, they encounter considerable forces that interact with them. Applying Faraday's law of electromagnetism and colloidal physics, as ironically charged minerals and asphaltenes flow through the MFC, the electrical charges on the crystal nuclei and the growing crystallites are affected at the surface. This alters the growth of the crystals in general and on specific planes as they are oriented in one direction and tumbled, allowing them to cluster together to form colloids on a microscopic level. This then allows nuclear seeding for the paraffins.

The total combined surface of the colloids collectively is exponentially greater than the casing surface of the production tubing causing the paraffin deposition to be on that of the colloids and less free paraffins in the crude oil to cause a paraffin zone. While in this paraffin coated colloidal state the surface tension and the mechanical adhesions of the sticky paraffins to one another and to the tubulars are reduced.

From recent, limited, observations in the field, MFC appear to affect the adhering properties of paraffin particles that form in the flowing oil. Paraffin particles formed in untreated oil appear to be gooey and tacky. Those in treated oil were more brittle and less tacky. The end result is a change in solubility and a lower cloud point (temperature at which paraffin starts to come out of solution). In addition, the temperature of deposition, viscosity, pour point are altered, all of which serve to inhibit paraffin and scale formation. A good analogy is to think of powder sugar and how it tends to stick to everything but when it is clustered together to form granular sugar it tends to roll off surfaces.

Over time the colloids of the treated crude will return to its normal state of randomness so close placement of the MFC uphole to where paraffin normally starts to form is essential to help the crude oil retain the colloidal effect and maintain the tubulars free of paraffin. Typically only one unit installed below the deepest paraffin zone will normally yield excellent results. Under certain conditions, 
multiple paraffin zones or high volume wells, that cause the colloids to break up and have return to its natural state, an additional MFC unit may be required to reform the colloids.

The only test data available to date is on the 6" transfer line from Battery \#3 to the central injection station. Prior to installation, the following volumes were measured on millipore tests using a standard .45 micron filter:

$$
\begin{aligned}
& \text { Jan } 7-180 \mathrm{ml} \\
& \text { Jan } 8-240 \mathrm{ml} \\
& \text { Jan } 9-300 \mathrm{ml} \\
& \text { Jan } 23-200 \mathrm{ml} \\
& \text { Mar } 3-190 \mathrm{ml}
\end{aligned}
$$

Following the installation of the magnetic fluid conditioners, the following results were obtained:

April $6-410 \mathrm{ml}$

April $21-380 \mathrm{ml}$

\section{ACTIVITY II.3 - INTEGRATION/VALIDATION}

\section{VALIDATION OF RESERVOIR CHARACTERIZATION - TASK II.3.1}

\section{Updating the Rock-Log Model}

Extensive work has been done on updating the rock-log model using data from the newly-drilled wells in the project area. The well log database was reviewed and compared to the data obtained from the new wells. Necessary edits were made, and the entire data set was normalized.

Porosity data from the new cores demonstrated some disparity with the porosities calculated from logs using the original algorithms of Phase I. The porosity algorithm used in Phase I was subsequently modified using the new data. This resulted in an overall decrease in calculated porosity, but produced a closer agreement with the core data.

The algorithm used in the calculation of water saturations was also modified. This involved varying the value of the cementation exponent " $\mathrm{m}$ " by rock type based upon the new electrical properties data obtained from the core. The value of " $\mathrm{m}$ " was varied as a function of porosity and rock type. Type 1 rocks have values of approximately 2 while Types 2, 3, and 4 have values in the range of 2.1 to 2.3. The saturation exponent " $n$ " values measured in the new cores did not appear unusual, so these were not varied as was "m".

Solutions were then run on the log suites of the 122 wells in the Phase I database and on 10 of the new 10 -acre wells. The new solutions were then loaded into the deterministic model being developed by SSI. The remaining 10-acre wells are still being worked on, and will be integrated with the full data set when finished. 


\section{Simulations}

The simulations for Section 362 are complete. This was the last section model that we were scheduled to simulate. The results of the section models indicate that the multi-layer (dual-porosity) technique is able to represent the reservoir performance quite well. However, there is evidence that boundary effects are present which are not always accounted for in these models. One example is that wells on the model boundaries are often more difficult to match than interior wells. This could result from the assumption that half (edge wells) or a quarter (corner wells) of the production/injection be included in the model. Areal variations in reservoir quality, or lack of symmetry in production or injection patterns, could result in the need to use significantly different fractions.

Another possible indication of boundary effects is that in some section models the pore volume had to be increased and in other models the pore volume was decreased. These changes were required in order to match reservoir pressures (and gas production). The required reduction in pore volume is often associated with sections which begin to produce late and/or have lower rates of production. It is possible that some of the pressure reduction in these sections is due to earlier and higher production in surrounding areas.

The full field model will resolve nearly all of the problems of boundary effects, especially if we can obtain completion, production, and injection data for one or two rows of wells outside of the North Robertson Unit. By the way, Susan King has provided us with all the North Robertson production/injection data through December 1997.

The construction of the full-field model has begun. The general dual-porosity miscible black oil framework of the model has been built and the structure and gross thickness arrays are in place. We are waiting for the previous half-foot $\log$ analysis results from D.K. Davies, along with their assessment of which wells will not change significantly in their new interpretations. These previous data will be used to generate preliminary net thickness and porosity arrays, and to confirm the permeability and water saturation characterizations. The preliminary data will be sufficiently accurate to build and test the model, and to begin history matching. The final net thickness and porosity arrays will be inserted when the data becomes available. As discussed in the last meetings, we will perform the summations of the half-foot log data, rather than D.K. Davies. This will allow us to quickly modify the net thickness criteria and produce new arrays based on the results of the simulations.

One of the most time-consuming phases of this work is the construction of the completion and production/injection histories of each well. In the full-field model we will have more than 300 wells. This work will proceed relatively quickly since we already have the production and injection data for all North Robertson Unit wells in a database. We just need to update it for the last quarter of 1997. We also have all the completion histories for the North Robertson Unit wells, including the new (1996) wells. We have already constructed simulator completion records for many of these wells since most of them fall within one of the section models. 
In the section model simulations, the productivity/injectivity index for each well active at the end of history is calibrated before proceeding to the prediction simulations. It is assumed in these simulations that the index does not change with time (other than changes resulting from fluid property and relative permeability changes). As we have discussed briefly in previous meetings, it appears that there may be a reduction in PI at the production wells for a period immediately following their completion. After this period of reduction, the PI's seem to stabilize until the well is re-completed. We have frequently seen this type of behavior in wells in other fields, particularly in wells with hydraulic fracs. The cause of the reduction can be real (i.e. partial closing of the frac, deposition of asphaltenes along the frac face, etc.) or apparent (draining of isolated sand lenses intersected by the frac). The predictions for wells that have produced for several years during history are good because they have entered the stabilized PI period. The predicted rates for wells that were completed just prior to the end of history tend to be high because their PI's are calibrated to values before stabilization. The initial production rates of wells drilled or recompleted in the prediction period tend to be low since their PI's were estimated from the stabilized values of surrounding wells.

\section{PUBLICATIONS AND PRESENTATIONS - TASK II.4.3}

Published Papers and Professional Meeting Presentations:

1997 Annual DOE/BDM International Reservoir Characterization Technical Conference, March 2-4, 1997, Houston, TX.

- Oral presentation and poster session on project material

- "Improved Characterization of Reservoir Behavior by Integration of Reservoir Performance Data and Rock Type Distributions."

Oklahoma Geological Society Circular, Platform Carbonates in the Southern MidContinent, (in press), K.S. Johnson, March 1997.

- "Environments of Deposition for the Clear Fork and Glorieta Formations, North Robertson Unit, Gaines County, Texas."

1997 DOE/BDM Annual Contractor Review Meeting, June 16-20, Houston, TX .

- Oral presentation

1998 PBS/SEPM Core Workshop, February 26, Midland, Tx.

- Display of core taken during DOE field demonstration 